Beatrice Didier, Stendhal ou la dictée du bonheur, Paroles, échos et écritures dans La Chartreuse de Parme

\title{
Philippe Andrès
}

\section{(2) OpenEdition}

\section{Journals}

Édition électronique

URL : http://journals.openedition.org/studifrancesi/36362

DOI : 10.4000/studifrancesi.36362

ISSN : 2427-5856

Éditeur

Rosenberg \& Sellier

\section{Édition imprimée}

Date de publication : 1 juillet 2005

Pagination : 180-181

ISSN : 0039-2944

\section{Référence électronique}

Philippe Andrès, «Beatrice Didier, Stendhal ou la dictée du bonheur, Paroles, échos et écritures dans La Chartreuse de Parme », Studi Francesi [En ligne], 145 (XLIX | I) | 2005, mis en ligne le 30 novembre 2015, consulté le 20 avril 2021. URL : http://journals.openedition.org/studifrancesi/36362 ; DOI : https:// doi.org/10.4000/studifrancesi.36362

Ce document a été généré automatiquement le 20 avril 2021.

\section{(c) $($ ) $\odot$ (8)}

Studi Francesi è distribuita con Licenza Creative Commons Attribuzione - Non commerciale - Non opere derivate 4.0 Internazionale. 


\title{
Beatrice Didier, Stendhal ou la dictée du bonheur, Paroles, échos et écritures dans La Chartreuse de Parme
}

\author{
Philippe Andrès
}

\section{RÉFÉRENCE}

BEATRICE DIDIER, Stendhal ou la dictée du bonheur, Paroles, échos et écritures dans La Chartreuse de Parme, Paris, Klincksieck, 2002, pp. 237.

1 Rares sont les ouvrages qui allient l'esprit d'analyse à l'esprit de synthèse, l'érudition à la clarté pédagogique, et procurent au lecteur une véritable délectation. Celui de Béatrice Didier est de ceux-là. Il s'agit de mettre à jour, sans pour autant l'épuiser, la fascination exercée par La Chartreuse de Parme.

Dans une première partie consacrée aux «Composantes» (pp. 9-76), Béatrice Didier nous livre les secrets de «L'histoire d'une dictée» (chapitre I, pp. 11-16), en l'absence du manuscrit. Ainsi faut-il être très attentif aux marginalia laissées par Stendhal sur les ouvrages qu'il lisait et qui forment le «journal reconstitué» de l'auteur d'après V. DeI Litto. La Chartreuse devra se lire sous le signe de l'oralité. Le chapitre II (pp. 17-23) s'intéresse aux Chroniques italiennes aux sources du «romanzetto» projeté par Stendhal qui transpose au XIX ${ }^{\mathrm{e}}$ siècle l'histoire d'Alexandre Farnèse et lui permet "d'exprimer sa déception devant la politique italienne de son temps, et son mépris pour LouisPhilippe» (p. 22). Le chapitre III (pp. 25-32) souligne le rôle omniprésent des «autoréférences»et invite à une lecture croisée entre la Chartreuse et Lucien Leuwen. Les «Échos» (chapitre IV, pp. 33-41) entre la littérature italienne et La Chartreuse sont fort nombreux. L'Arioste, la structure de La Divine Comédie de Dante, Pétrarque, les chroniques italiennes sont autant d'éléments présents en filigrane dans le roman. De même le théâtre et l'opéra ponctuent le texte comme autant de références passées au tamis du souvenir. Le chapitre V («Des anti-mémoires», pp. 43-56) nous invite à 
considérer le roman "comme une création qui tend à s'écarter le plus possible de la vie» (p. 44), à l'opposé de la tradition critique stendhalienne. En effet il est impossible de cerner «un moi fuyant au gré des instants, au gré des années» (p. 48) et, au lieu de vouloir à tout prix établir des analogies entre Fabrice et Mosca comme autant de projections du romancier, Béatrice Didier nous invite à nous interroger plutôt sur les rythmes d'une vie et d'une écriture, sur la nécessité de l'enfermement pour la création. Pour clore la première partie, le chapitre VI («Improvisation et canevas», pp. 57-76) s'intéresse à la représentation visuelle des lieux, au souci stendhalien des realia et développe l'idée que «le roman a pris le relais du mythe» (p. 64) à partir de modèles structurants, comme les chroniques, les romans picaresques ou les mémoires. Aussi le lecteur a-t-il «le sentiment d'une extraordinaire fécondité de l'improvisation» (p. 70) qui sans doute se trouve lié au choix de Stendhal de dicter son roman à un copiste, au cours de nombreuses séances (environ soixante-dix). Et le roman tout entier semble bruire d'une oralité aboutissant au «silence final» (p. 75).

3 La deuxième partie («Organisation de l'œuvre», pp. 77-152) s'ouvre sur une approche des «Rappels, annonces et réitérations du récit» (pp. 79-94). B. Didier analyse finement les procédés narratifs. Le roman tout entier «obéit à des lois de structuration» (p. 0). Le chapitre II (pp. 95-107) se consacre à l'étude de l'épistolarité dans le roman, comme présence réelle ou mentionnée de nombreuses lettres. Le chapitre suivant («Paroles et silences», pp. 109-124) s'interroge sur les différents types de dialogues, intégrés à l'action ou délibératifs et politiques, et l'on constate une tendance à l'abrègement de la forme dialogique. Quant aux «Descriptions et portraits» (chapitre IV, pp. 125-137), ils s'intègrent plutôt dans une focalisation interne, et ce de manière atomisée. La description est souvent elliptique et le portrait est «sous-tendu par une dialectique du regard» (p. 137). Le dernier chapitre s'intéresse au jeu entre «le narrateur et son auditeur» (pp. 139-152), au coeur même d'une ironie plurielle.

4 La troisième partie («Une voix souveraine», pp. 153-237) s'ouvre sur un chapitre centré sur l'analyse des personnages à l'identité incertaine» (pp. 155-170). Ainsi, un halo d'incertitude rehausse le charme de Fabrice. Paradoxalement, «la rhétorique des nombres» (chapitre II, pp. 171-185) qui abondent dans la Chartreuse ne brise pas cette incertitude séductrice. La précision des dates est liée au flou des âges; l'évaluation des fortunes est omniprésente mais s'inscrit plus dans une esthétique du chiffre que par effet de réel. Au chapitre III («Épaisseur du temps et allégresse du récit», pp. 187-204), Didier s'interroge sur les rapports complexes entre le temps historique et les «glissements» stendhaliens, comme la période entre 1815 et 1830 où «l'Histoire subit une sorte de rétrécissement» (p. 191). Parfois le récit se dilate et il existe comme un «décalage entre le temps historique et le temps des personnages» (p. 194). Les arrêts de la temporalité sont toujours les marques symboliques du Bonheur. Didier, à l'inverse du concept de «vitesse du récit» de Genette, propose la notion «d'allégresse du récit» impliquant la part de subjectivité du lecteur. Le chapitre IV («Créer l'espace», pp. 205-220) souligne le paradoxe d'un «progressif rétrécissement de l'espace» (p. 212). Finalement, au cours du dernier chapitre («Le pouvoir d'une voix», pp. 221-237), Didier met l'accent sur la théatralisation romanesque dans la représentation du pouvoir politique. Parme se trouve ainsi «transfigurée par la présence de l'art» (p. 234).

5 Le plaisir que nous avons pris à la lecture de cet ouvrage ne peut que nous inviter à relire La Chartreuse de Parme pour notre plus grand bonheur, puisque mystère et charme demeurent encore dans notre mémoire. 